http://dx.doi.org/10.4314/jae.v18i1.10

\title{
Private Sponsorship of Rural Development Broadcasts on Radio in Southwest Nigeria
}

\section{Badiru, I.O and Adekoya, A.E}

Department of Agricultural Extension and Rural development, Faculty of Agriculture and Forestry, University of Ibadan, Nigeria Tel: +2348034660732Ｅ-mail: bodebadru@yahoo.com

\section{Abstract}

The study explored the private sponsorship prospects of rural development broadcasts (RDBs) on radio in Southwest Nigeria. Forty private sponsors of programmes were randomly selected for the study. Questionnaire was used to collect data on private sponsorship status of $R D B s$, reasons for broadcasts' sponsorship, factors hindering RDBs sponsorship and willingness to sponsor RDBs. Frequency counts and binomial logit were used to analyse the resulting data. There was a low sponsorship status (26.7\%) of RDBs among the sponsors. Inadequate knowledge of benefits derivable from sponsorship of RDBs (30\%) hindered sponsorship of RDBs while increased sensitisation on these benefits (40\%) would enhance their sponsorship status. Increased brand awareness was the most important reason (46.7\%) that propelled sponsors to support broadcasts. Most sponsors (66.7\%) would be willing to support RDBs on radio. Sponsors' characteristics were not significantly related to their willingness to sponsor RDBs. Stakeholders in rural development broadcasting should therefore step up their sensitisation campaigns among prospective sponsors to intimate them of the listenership strength of RDBs in the area in order to improve the sponsorship situation.

Keywords: Willingness, broadcast, sponsorship 


\section{Introduction}

Mass media are crucial in the rural development process. Although, their role is supportive, it has become highly germane in information due to the need to enhance the performance of the extension delivery system. In line with this thinking, many agricultural development programmes (ADPs), in addition to having village extension agents (VEAs) on the field also have broadcasts on the mass media, especially the radio. This is because radio is popular and readily available to farmers. It removes geographical and physical barriers, thus getting messages to the listeners instantly (Tabing, 2002). This therefore confers on it great potentials for the development of the Nigerian rural areas since development broadcasts on it are well listened to by rural dwellers (Adekoya and Badiru, 2012; Olowu, Anyanwu and Obinne, 2004).

However, the potentials of the radio are yet to be fully exploited in turning the rural sector around in Nigeria. Although, a number of rural development broadcasts are aired periodically, they constitute a small proportion of total radio broadcasts and many are usually short-lived. The long running ones are mostly government sponsored, thus having serious implications on their sustainability because broadcasting in Nigeria is fast moving away from being a social service to becoming a serious commercial endeavour (Zayyad, 2009; Muhammed, 2008 and Folarin, 1998). Oladeji and Badiru (2007) found that the sustainability of rural development broadcasts is being hampered like other broadcasts by inadequate sponsorship/advertisements. This suggests the need for seeking their sustenance from other sources apart from government to enhance their sustainability.

In Nigeria, corporate organisations such as Unilever, Nestle, Coca-Cola and more recently, MTN, Globacom and Airtel to mention a few, are involved in the sponsorship of a wide variety of programmes in the media. Walliser (2003), while reviewing the works of other authors implied that, although affinity between a sponsor's product and sponsored activity is essential for sponsorship (for instance, an agrochemical company will be more inclined towards sponsoring an agricultural broadcast), it does not mean that rural dwellers that are the primary targets of rural development broadcasts are also not consumers of other products such as Coca-Cola and telecommunications, and are as well targets of these companies' customer drive. According to Walliser (2003), sponsorship is aimed at enhancing image and increasing awareness for brands and/or companies. Therefore, there is need for sponsorship drive within and beyond the traditional public rural development agencies where sponsorship of rural development broadcasts are often sought to examine such potential sponsors' needs and expectations when designing rural development broadcasts. This is because sponsorship is customer-oriented; the higher the number of listeners or potential listeners of a particular broadcast, the greater the chances of securing a sponsor for such a broadcast, provided the listeners are potential customers for the sponsors.

Rural development broadcasts in Nigeria have wide listenership base, yet do not stay long on air except they are in-house broadcasts of the radio station or sponsored by a government agency, in comparison with sport and entertainment broadcasts which 
are sponsorship and advert-driven. This study therefore set out to investigate the willingness of sponsors to support rural development broadcasts on radio in Southwest Nigeria with specific objectives to;

(i) examine the characteristics of the sponsors;

(ii) examine sponsorship status of rural development broadcasts among sponsors;

(iii) determine sponsors' most important reasons for supporting broadcasts;

(iv) describe what makes rural development broadcasts unattractive to private sponsorship;

(v) determine relationship between characteristics of sponsors and their willingness to support rural development broadcasts.

\section{Methodology}

The study was carried out in the Southwest geopolitical zone of Nigeria. Three of the states (Ogun, Ondo and Oyo) in the zone were randomly selected. A list of 60 organisations that sponsor broadcasts was generated from radio stations in the selected states, while 40 of the sponsors were selected using the simple random sampling technique to achieve a 67 percent proportion of the sampling frame. Pretested questionnaire with a reliability coefficient of 0.72 was used to collect data for the study. The instrument was administered on the corporate affairs/advertisement managers of the selected companies with the help of enumerators, while thirty returned and correctly filled questionnaires were analysed.

Respondents were asked to state companies' characteristics such as staff strength, measured as actual number of staff on the pay roll of the company while product orientation was dichotomised into agricultural related and non-agricultural related. Reason for supporting broadcasts was measured by asking respondents to tick the most important reason why they support broadcast from the options: increase in sales/profit, image enhancement, increased brand awareness, corporate social responsibility etc. Sponsorship status was measured as Yes or No, while respondents also provided factors that make rural development broadcasts unattractive for sponsorship. Willingness to support rural development broadcasts was measured using 32 attitudinal statements stated in positive and negative forms which were rated on a Likert-type scale. Negative statements' scores were reversed before the scores were computed. The maximum possible score was 160 , while the least possible score was 32. The mean score was found and scores above the mean were categorised as more willing and those below as less willing to support rural development broadcasts. 


\section{Results and Discussion}

\section{Characteristics of sponsors}

The mean company size was 1,075 staff (Table 1). Using IFC (2012) and Ekpenyong and Nyong (1992) classification, majority of the companies sampled $(70.0 \%)$ were medium to large scale that is, had above 50 paid employees. This finding implies that many of the companies are big enough to have fully developed departments devoted to corporate image promotion and as a result viable for sponsorship of rural development broadcasts among other broadcasts. The table further shows that on product orientation, a larger proportion (56.7\%) of the companies sampled was of the non-agricultural product orientation, though a sizeable proportion $(43.3 \%)$ had agricultural product orientation. This implies that sponsored activity and sponsored product' affinity are moderately possible and as a result, rural development broadcasts have a fair chance of being favourably predisposed to by the sampled sponsors.

\section{Table 1: Characteristics of sponsors}

\begin{tabular}{llll}
\hline Variable & Category & Frequency & Percent \\
\hline Company size & $15-100$ & 10 & \\
& $101-1000$ & 13 & 43.4 \\
& $1001-7000$ & 7 & 23.3 \\
Product orientation & Agricultural and agro-allied & 13 & 43.3 \\
& Non-agricultural & 17 & 56.7 \\
\hline
\end{tabular}

\section{Sponsorship status of rural development broadcasts}

It was revealed in Table 2 that less than half of the sponsors had ever engaged in the sponsorship of rural development broadcasts, while a meagre $26.7 \%$ were still engaged in rural development broadcast sponsorship. This is in accordance with earlier submissions that rural development broadcasts are currently the exclusive preserve of public sponsors, a trend which may not make the activity a sustainable one. This situation is worrisome because of obvious government's policy inconsistency in the country. Therefore, leaving the sponsorship of the sector in the hands of the government is not the best. 
Table 2: Companies' sponsorship status of rural development broadcasts

\begin{tabular}{lllll}
\hline Category & \multicolumn{2}{c}{ Past } & \multicolumn{2}{c}{ Present } \\
\cline { 2 - 5 } & & & & \\
& & & & \\
& 13 & 43.3 & 8 & 26.7 \\
Yes & 17 & 56.7 & 22 & 64.3 \\
No & 17 & & & Prequency \\
\hline
\end{tabular}

\section{Reasons for sponsorship}

The interest of companies was the reason why majority (93.3\%) of sponsors support broadcasts (Table 3 ). This implies that sponsors would likely support rural development broadcasts if there are inherent benefits in them. This agrees with the observations of Stockard (2008), Walliser (2003) and Folarin (1998) that broadcasts are supported by sponsors with the aim of getting access to the consciousness of the listeners of such broadcasts.

Table 3: Sponsors' most important reason for sponsorship

\begin{tabular}{lll}
\hline Variable & Frequency & Percent \\
\hline Increase in sales/profit & 10 & 33.3 \\
Image enhancement & 4 & 13.3 \\
$\begin{array}{l}\text { Increased brand awareness } \\
\begin{array}{l}\text { Corporate Social Responsibility } \\
\text { (CSR) }\end{array}\end{array}$ & 14 & 46.7 \\
\hline
\end{tabular}

Reasons

why sponsorship is unattractive

Results in Table 4 showed that the reasons why sponsors find rural development broadcasts unattractive for sponsorship include inadequate knowledge of the benefits derivable from the sponsorship of rural development broadcasts $(30 \%)$, while many shared the belief that rural development broadcasts do not have wide listenership 
(26.7\%). These findings suggest an information gap that needs to be filled by practitioners in the field of rural development broadcasts to make information available to all and sundry on the listenership status of rural development broadcasts in the zone.

Meanwhile, many sponsors (40\%) believed that increased sensitisation on the benefits of rural development broadcasts would make their sponsorship more attractive to sponsors; while a considerable proportion (23.3\%) opined that an increased listenership base would enhance their attractiveness. In the same vein, another $23.3 \%$ indicated a need to improve the packaging and delivery of rural development broadcasts for enhanced sponsorship. Overall, most of the respondents $(73.3 \%)$ indicated their readiness to sponsor rural development broadcasts if the suggestions given are considered.

Table 4: Reasons why sponsors find the sponsorship of rural development broadcasts

unattractive

\section{Category}

Frequency Percent

\begin{tabular}{lll}
\hline Inadequate knowledge of the benefits & 9 & 30 \\
Presenters do not come up with good proposal & 3 & 10 \\
Programmes do not have wide listenership & 8 & 26.7 \\
Programmes are not well packaged & 3 & 10 \\
Management policy does not support such & 2 & 6.7 \\
Programmes are not well delivered & 2 & 6.7 \\
Others & 3 & 10 \\
Enhancing the sponsorship of rural development broadcasts & & 40 \\
Increased sensitisation on the benefits of rural development broadcasts & 12 & 10 \\
Improvement in the quality of sponsorship proposals & 3 & 23.3 \\
Increased listenership base & 7 & 23.3 \\
Improved programme packaging and delivery & 7 & 3.3 \\
Others & 7 & 26.7 \\
Readiness to sponsor rural development broadcasts if constraints are addressed & 22 & 73.3 \\
Yes & 8 & 2 \\
No & 7 & \\
\hline
\end{tabular}




\section{Willingness to support rural development broadcasts}

Majority $(66.7 \%)$ of the respondents in Table 5 perceived that they can advertise products on rural development broadcasts. This implies a high prospect for the sponsorship of rural development broadcasts among the sponsors. Most $(70.0 \%)$ of the sponsors also agreed that sponsorship of rural development can be sustained subject to continued listenership. This corroborates earlier assertion by the author that listenership is a determinant of broadcasts' sustainability. This, and the fact that majority of the sponsors $(66.7 \%)$ agreed that all types of companies can benefit from sponsoring rural development broadcasts therefore imply that the sponsorship prospect of rural development broadcasts in the study area is very high. 


\section{Table 5: Distribution of sponsors on their willingness to support rural development broadcasts}

\begin{tabular}{|c|c|c|c|c|c|}
\hline Statements & SA & A & $\mathbf{U}$ & $\mathbf{D}$ & SD \\
\hline $\begin{array}{l}\text { We can reach more consumers of our products by advertising on rural development } \\
\text { broadcasts. }\end{array}$ & 6.7 & 60 & 20 & 13.3 & 0 \\
\hline Rural development broadcasts are only good for agro - allied companies. & 3.3 & 6.7 & 20 & 60 & 10 \\
\hline We will sponsor rural development broadcasts if we add inputs into the final broadcast. & 3.3 & 33.3 & 46.7 & 13.3 & 3.3 \\
\hline Rural development broadcasts sponsorship will not augur well for our corporate image. & 6.7 & 3.3 & 16.7 & 53.3 & 20 \\
\hline $\begin{array}{l}\text { Rural development broadcasts can be sponsored as long as a cross - section of the } \\
\text { population watch/listen to it. }\end{array}$ & 13.3 & 56.7 & 20 & 10 & 0 \\
\hline We are not willing to have anything to do with rural development broadcasts. & 3.3 & 10 & 20 & 43.3 & 23.3 \\
\hline All types of company can benefit from sponsoring rural development broadcasts. & 26.7 & 40 & 26.7 & 6.7 & 0 \\
\hline $\begin{array}{l}\text { The category of people listening to rural development broadcasts is not our target } \\
\text { audience. }\end{array}$ & 3.3 & 13.3 & 23.3 & 56.7 & 3.3 \\
\hline $\begin{array}{l}\text { Rural development broadcasters possess enough persuasive skills for attracting } \\
\text { sponsors. }\end{array}$ & 6.7 & 33.3 & 33.3 & 23.3 & 3.3 \\
\hline Quality of rural development broadcasts is poor and uninspiring & 3.3 & 30 & 33.3 & 30 & 3.3 \\
\hline Rural development broadcasters do not merit sponsors' money & 3.3 & 6.7 & 20 & 60 & 10 \\
\hline Rural development broadcasts quality is okay & 0 & 33.3 & 40 & 23.3 & 3.3 \\
\hline Sponsoring rural development broadcasts has never occurred to us. & 10 & 20 & 23.3 & 30 & 13.3 \\
\hline $\begin{array}{l}\text { Supporting the development of agriculture and the rural areas is key to our national } \\
\text { development }\end{array}$ & 20 & 46.7 & 16.7 & 10 & 6.7 \\
\hline The society has no need for rural development broadcasts. & 10 & 6.7 & 16.7 & 46.7 & 20 \\
\hline We are willing to spend a little on agric broadcasts in the future. & 3.3 & 26.7 & 26.7 & 36.7 & 6.7 \\
\hline The situation is just not right for the sponsorship of agric broadcasts. & 3.3 & 16.7 & 30 & 40 & 10 \\
\hline $\begin{array}{l}\text { We are inclined to sponsor the next available rural development broadcast proposal } \\
\text { brought to us if the conditions are okay. }\end{array}$ & 3.3 & 43.3 & 33.3 & 20 & 0 \\
\hline Rural development broadcasts are not bad but our management policies do not favour it. & 10 & 10 & 43.3 & 33.3 & 3.3 \\
\hline
\end{tabular}

${ }^{\star}$ Figures are percentages 
The mean score for willingness of sponsors to support rural development broadcasts was 114.4. This was used to categorise the scores into less willing and more willing (Table 6). Based on the categorisation, more of the sponsors (66.7\%) were willing to support rural development broadcasts. This suggests that many of the sponsors were favourably disposed to the sponsorship of rural development broadcasts. This willingness can be turned into actual sponsorship if the sponsors are contacted in a convincing manner.

Table 6: Willingness categories of sponsors based on mean score

\section{Willingness Category $\quad$ Frequency Percent}

\begin{tabular}{llll}
\hline Less willing & 10 & 33.3 & $\bar{x}=114.4$ \\
More willing & 20 & 66.7 & \\
\hline
\end{tabular}

\section{Predicting willingness to sponsor}

Binomial logit analysis in Table 7 showed that sponsors' characteristics such as size $(\beta=0.635, p>0.05)$ and product orientation $(\beta=-0.378, p>0.05)$ had low import in predicting willingness to sponsor rural development broadcasts. This suggests that many of the sponsors, irrespective of their product orientation and size, were favourably disposed to the sponsorship of rural development broadcasts if contacted for sponsorship in a convincing manner. This is in agreement with Stockard (2009) that sponsors are only interested in getting the attention of potential customers who in this case, are the listeners of sponsored broadcasts.

Table 7: Binomial Logit analysis of sponsors' characteristics and willingness to sponsor rural development broadcasts

\begin{tabular}{llll}
\hline Variable & Coefficient & t-ratio & p-value \\
& & & \\
\hline Constant & 0.8755 & 0.628 & 0.5302 \\
Size & 0.1944 & 0.635 & 0.5253 \\
Product orientation & -0.3076 & -0.378 & 0.7051 \\
\hline
\end{tabular}


Sample size $=30$

Chi-squared $=0.72298$

Degree of freedom $=2$
Log likelihood function $=-17.88769$

Restricted log likelihood $=-18.24918$

Level of significance $=0.05$

\section{Conclusions and recommendations}

The study showed a high prospect for the private sponsorship of rural development broadcasts on radio in Southwest Nigeria. Sponsors were motivated by benefits derivable from sponsorship of broadcasts such as increase in the awareness of the sponsors' brands or products but had poor knowledge of the benefits inherent in the support of rural development broadcasts, thus discouraging them from supporting such. However, most of the sponsors expressed their readiness to support rural development broadcasts on radio if the constraints are addressed. Willingness of sponsors to be involved in rural development broadcasts cuts across board, irrespective of the staff strength and product orientation of the sponsoring companies.

It is therefore recommended that rural development broadcasts' stakeholders should increase their sensitisation effort on the benefits derivable from the sponsorship of rural development broadcasts to the sponsors. Focus of the sensitisation should be on the number of listeners or potential customers who could be reached through such broadcasts. This could be done by making public survey results on rural development broadcasts' listenership available to sponsors, as well as applying innovative approaches like introducing phone-in segments to programme packaging to give the general public an opportunity to hear from rural development broadcasts' listeners live, thus confirming their wide audience base.

\section{References}

Adekoya, A.E and Badiru, I.O (2013): Listenership of Radio Agricultural Broadcasts in Southwest Nigeria, Journal of Applied Environmental Education \& Communication Vol. 11:3-4,189-196 http://dx.doi.org/10.1080/1533015X.2012.777292

Ekpenyong, D.B and Nyong, M.O. (1992). Small and medium-scale enterprises in Nigeria: their characteristics, problems and sources of finance. Research consortium retrieved on $24^{\text {th }}$ January, 2013 from http://www.aercafrica.org/documents/rp16.pdf 
Folarin, B. (1998). Theories of mass communication: An introductory text, Ibadan, Stirling Holden Publishers (Nig.) Ltd. 131 pgs.

International Finance Corporation (IFC) (2012). Interpretation note on small and medium enterprises and environmental and social risk management, IFC publication, July 1,2012 retrieved on $6^{\text {th }}$ June, 2013, 6 pages from de7d92804a29ffe9ae04af8969adcc27/InterpretationNote_SME_2012.pdf?MOD= AJPERES

Muhammad, I. (2008). Private radio ownership and objective news reporting in Nigeria: A study of Nagarta radio, Kaduna. B.Sc thesis submitted to the department of mass communication, faculty of social sciences, Ahmadu Bello University, Zaria. April 16, 2008.

Oladeji, J. O. and Badiru, I. O. (2007). Employment prospects of agricultural extension and rural development graduates in the broadcasting industry of Southwest Nigeria. Research journal of applied sciences 2 (3): 319 - 322 retrieved from www.medwelljournals.com/new/5detail.php on 11the June 2007.

Olowu, T. A. (1993). Audience survey of radio listening group in Osun state. In FAO project report no. NIR/87/074, Strengthening Agriculture Extension in Nigeria, FAO, Lagos, Lagos state.

Olowu, T.A, Anyanwu, A.C and Obinne, P. (2004). Farm radio network; a baseline survey of six states of Nigeria. Farm radio network project (TCP/NIR/3002A). Report submitted to Food and Agriculture Organization of United Nations (FAO) on December $7^{\text {th }}, 2004$ retrieved on $13^{\text {th }}$ January 2010 from http://farmradionetwork.org/pdfdocs/FRN\%20Project\%20Baseline\%20Survey\%2 ORepor t\%20Final.pdf.

Stockard, N. (2008). Why do sponsorships? Retrieved on $27^{\text {th }}$, August 2012, from http://ezinearticles.com/?Why-Do-Sponsorships?\&id=1315669

Tabing (2007). How to do community radio; a primer for community radio operators retrieved from www.unesco.org/webworld/community radio on 19th June 2007.

Walliser, B. (2003). An international review of sponsorship research: extension and update. International journal of advertising. World advertising research center, U.K., 22 (1).

Yahaya, M. K. and Badiru, O. I. (2002). Measuring the impact on farmers of agricultural radio and television programs in Southwest Nigeria. Journal of applied communications 86 (3), pg. 24 - 36 Florida, USA. 
Journal of Agricultural Extension Vol.18 (1) June, 2014 ISSN 1119-944X

Zayyad, H.R. (2009). Privatisation and commercialisation in Nigeria retrieved from

http://unpan1.un.org/intradoc/groups/public/documents/AAPAM/UNPAN028228.p df on 13th January 2009. 